\title{
Effect of Initial Annealing Temperature on Microstructural Development and Microhardness in High-Purity Copper Processed by High-Pressure Torsion**
}

\author{
By Saleh N. Alhajeri, Abdulla I. Almazrouee, Khaled J. Al-Fadhalah, and Terence G. Langdon
}

[*] Dr. S. N. Alhajeri, Dr. A. I. Almazrouee

Department of Manufacturing Engineering, College of Technological Studies, P.A.A.E.T., P.O. Box 42325, Shuwaikh 70654, Kuwait

E-mail: sn.alhajeri@paaet.edu.kw

Dr. K. J. Al-Fadhalah

Department of Mechanical Engineering, College of Engineering \& Petroleum, Kuwait University, P.O. Box 5969, Safat 13060, Kuwait

Prof. T. G. Langdon

Materials Research Group, Faculty of Engineering and the Environment, University of Southampton, Southampton SO17 1BJ, UK

[**] The authors acknowledge the support provided by the Public Authority for Applied Education and Training (PAAET) (Grants Nos. TS-12-13 and TS-12-03) and Kuwait University General Facility (Grant No. GE 01/07) for sample preparation, OM and the EBSD measurements. The work of one of us was supported by the European Research Council under ERC Grant Agreement No. 267464-SPDMETALS (TGL).

The effect of the initial annealing temperature on the evolution of microstructure and microhardness in high purity $\mathrm{OFHC} \mathrm{Cu}$ was investigated after processing by HPT. Disks of $\mathrm{Cu}$ were annealed for one hour at two different annealing temperatures, 400 and $800^{\circ} \mathrm{C}$, and then processed by HPT at room temperature under a pressure of $6.0 \mathrm{GPa}$ for $1 / 4,1 / 2,1,5$ and 10 turns. Samples were stored for 6 months after HPT processing to examine the self-annealing effects. Electron backscattered diffraction (EBSD) measurements were recorded for each disk at three positions: center, mid-radius and near edge. Microhardness measurements were also recorded along the diameters of each disk. Both alloys showed rapid hardening and then strain softening in the very early stages of straining due to self-annealing with a clear delay in the onset of softening in the alloy initially annealed at $800^{\circ} \mathrm{C}$. This delay was due to the relatively larger 
initial grain size compared to the alloy initially annealed at $400^{\circ} \mathrm{C}$. The final microstructures consisted of homogeneous fine grain sizes having average sizes of $\sim 0.28$ and $\sim 0.34 \mu \mathrm{m}$ for the alloys initially annealed at 400 and $800^{\circ} \mathrm{C}$, respectively. A new model is proposed to describe the behavior of the hardness evolution by HPT in high purity OFHC Cu. 


\section{Introduction}

The processing of metals and alloys by high pressure torsion (HPT) has been recognized over the last two decades as one of the most important severe plastic deformation (SPD) techniques. ${ }^{[1]}$ By comparison with other SPD procedures, HPT leads to exceptional grain refinement in bulk polycrystalline solids with processed grain sizes in the submicrometer or even nanometer level ${ }^{[2,3]}$ and with very high fractions of grain boundaries having high angles of misorientation. ${ }^{[4]}$ In processing by HPT, a sample in the form of a thin disk or ring is placed between two massive anvils and subjected concurrently to a high applied pressure and torsional straining. The equivalent von Mises strain imposed on the disk, $\varepsilon_{\mathrm{eq}}$, is calculated from the relationship ${ }^{[5,6]}$ :

$$
\epsilon_{e q}=\frac{2 \pi r N}{\sqrt{3} h}
$$

where $r$ is the radius of the disk, $N$ is the number of turns and $h$ is the thickness of the disk. It is readily apparent from Eq. (1) that the equivalent von Mises strain is directly proportional to the distance from the center of the disk. Thus, the theoretical relationship implies that the imposed strain is zero at the center of the disk where $r=0$ and the strain is a maximum at the edge of the disk thereby leading to inhomogeneities in the microstructures after processing by HPT. In practice, however, experiments show that in most metals the microstructure gradually evolves and becomes reasonably homogeneous across the disk after large numbers of revolutions. ${ }^{[7]}$

The effect of straining on the evolution of microstructural homogeneity is generally investigated after different numbers of turns either by directly studying the microstructure or by recording the microhardness across each disk. These measurements show that generally there is an agreement with the theoretical relationship in the early stages of straining where there is inhomogeneity with smaller grain sizes and higher hardness values near the edges of the disks by 
comparison with the centers. However, with increasing number of turns the microstructures usually evolve towards homogeneity and many metals exhibit a complete homogeneity at high numbers of turns. Materials showing this behavior include $\mathrm{Al},{ }^{[3,8-13]} \mathrm{Cu},{ }^{[14-16]} \mathrm{Ti},{ }^{[17-19]} \mathrm{Mg},{ }^{[20-23]}$ $\mathrm{Fe},{ }^{[24-26]} \mathrm{Ni}^{[27,28]}$ and numerous others metals and alloys. ${ }^{[29,30]}$ Nevertheless, some materials show a different type of behavior when processed by HPT. For example, in the early stage of straining high-purity (99.99\%) Al exhibits a higher hardness at the center of the disk and this value decreases with increasing straining until it reaches a homogeneous high hardness compared to the annealed condition. ${ }^{[31-33]}$ Similar behavior was also reported in high-purity (99.99 \%) $\mathrm{Zn}^{[34]}$ and pure $(99.9 \%) \mathrm{Mg} \cdot{ }^{[35]}$ By contrast, some metals such as the $\mathrm{Zn}-22 \% \mathrm{Al}$ eutectoid alloy and the $\mathrm{Pb}-62 \% \mathrm{Sn}$ eutectic alloy show different behavior where the hardness decreases significantly with increasing straining and ultimately reaches a homogeneous or saturation hardness that is lower than in the annealed condition. ${ }^{[36]}$ These three different types of hardening behavior may be effectively illustrated as in Figure $1^{[37]}$ where the separate models delineate hardening without recovery, hardening with subsequent recovery and an overall weakening.

Very recent HPT investigations on high-purity oxygen-free high conductivity (OFHC) $\mathrm{Cu}$ revealed additional complications that occur in the very early stages of straining. ${ }^{[38,39]}$ Specifically, it was found that the hardness initially increased and then decreased and thereafter increased again to reach homogeneity at a higher level of hardness. The softening in hardness during the early stages of straining was attributed in these experiments to dynamic recrystallization. ${ }^{[38]}$ In addition, the microhardness of the high-purity OFHC $\mathrm{Cu}$ disks was examined immediately after processing by HPT and then the disks were stored at room temperature (RT) for periods up to 6 weeks. ${ }^{[39]}$ Under these conditions, there was evidence for self-annealing that evolved with time in the discs processed through $1 / 2$ or 1 turn whereas there 
was a significant drop in hardness near the edges of the discs after storage for $2-6$ weeks. At large strains through 5 and 10 turns, there was no evidence for this self-annealing effect. Another HPT study on OFHC $\mathrm{Cu}$ showed that the texture during the early stages of straining was a mixture of shear and recrystallization textures and this accompanied the softening. ${ }^{[40]}$ These unusual effects were confined to the early stages of HPT processing because at higher strains the texture evolved into a simple shear texture and the microstructure became homogeneous and consisted of an array of ultra-fine grains.

Based on a comprehensive assessment of these earlier results, the objective of the present investigation was to explore the effect of the annealing temperature, and thus the initial grain size, on the evolution of microstructure and microhardness in OFHC $\mathrm{Cu}$ after processing by HPT. Specifically, the investigation was designed to examine the effect of the initial grain size on the formation of recrystallized grains, and thus on the hardness softening, during the initial stages of HPT straining. The OFHC Cu disks were subjected initially to two different annealing temperatures and then the disks were processed by HPT to different numbers of turns. The evolution of the microstructures was examined using optical microscopy (OM) and electron backscattered diffraction (EBSD) and the evolution of the microhardness was recorded along the diameter of each disk to permit a direct comparison between the two annealing conditions.

\section{Experimental material and procedures}

The experiments were performed using $10 \mathrm{~mm}$ diameter disks of OFHC copper of 99.99+ wt $\%$ purity: the chemical composition of the material was given earlier. ${ }^{[38]}$ The material was received initially in the form of $10 \mathrm{~mm}$ diameter rods. One rod was annealed for $1 \mathrm{~h}$ at $400^{\circ} \mathrm{C}$ which is close to $\sim 0.5 T_{\mathrm{m}}$ where $T_{\mathrm{m}}$ is the absolute melting temperature and the other rod was annealed for $1 \mathrm{~h}$ at $800^{\circ} \mathrm{C}$ which is $\sim 0.8 T_{\mathrm{m}}$. After annealing, the rods were cut into disks having 
thicknesses of $\sim 0.8 \mathrm{~mm}$. The HPT processing was conducted at RT under an applied pressure of 6.0 GPa for numbers of turns, $N$, of $1 / 4,1 / 2,1,5$ and 10 . The pressure was applied with a concurrent rotation speed of $1.0 \mathrm{rpm}$. All of the HPT processing was performed under quasiconstrained conditions where there is a very limited outflow of material around the edge of the disk during processing. ${ }^{[41]}$

Following processing by HPT, each disk was polished to a mirror-like surface and measurements of the Vickers microhardness, Hv, were taken along four diameter lines arranged on each disk surface at $45^{\circ}$ increments. The individual datum points were separated by $0.25 \mathrm{~mm}$ to a distance of $1.5 \mathrm{~mm}$ on either side of the center of each disk and then they were separated by $0.5 \mathrm{~mm}$ thereafter. The measurements were recorded using a Buehler MicroMet Hardness Tester using an applied load of $200 \mathrm{gf}$ and a dwell time of $15 \mathrm{~s}$. Microhardness measurements were taken both after HPT processing and in the annealed unprocessed condition. The average value for each datum point was recorded and these average values were then plotted against the distance along the diameter of each disk.

Another set of HPT disks was prepared for microstructural examination. First, samples were prepared for $\mathrm{OM}$ by chemical etching at ambient temperature using a mixture of $50 \mathrm{ml}$ of distilled water and $50 \mathrm{ml}$ of nitric acid. Second, samples were prepared for microstructural evaluation by EBSD by electropolishing using a solution of 25\% phosphoric acid, $20 \%$ ethanol, and $10 \%$ propanol in water. The OM examinations were performed using a Ziess (Axio-Imager) optical microscope. The grain size and microstructures were analyzed using an HKL Channel-5 EBSD detector interfaced to a JEOL F7001 field-emission scanning electron microscope (SEM) operating at $20 \mathrm{kV}$. The EBSD measurements were made on each disk surface at three positions: near the center of the disk, at the mid-radius position and near the edge. The grain boundaries are 
presented in the EBSD maps such that the low-angle boundaries (LABs) with a misorientation angle below $15^{\circ}$ are depicted as thin grey lines and the high-angle boundaries (HABs) with a misorientation angle above $15^{\circ}$ as solid black lines.

To examine the self-annealing effect, the microstructure and microhardness data were recorded in this study after HPT followed by storage of the samples at RT for a period of $\sim 6$ months.

\section{Experimental results}

\subsection{Microstructures before and after HPT}

The optical micrographs in Figure 2 show the microstructures of the annealed samples of OFHC copper at different magnifications: Figures 2(a) and (b) show the effect of annealing for 1 $\mathrm{h}$ at $400^{\circ} \mathrm{C}$ where the average grain size is $\sim 15.5 \mu \mathrm{m}$ and Figures 2(c) and (d) show the effect of annealing for $1 \mathrm{~h}$ at $800^{\circ} \mathrm{C}$ where the average grain size is $\sim 28 \mu \mathrm{m}$. For both annealing conditions, there are high fractions of annealing twins in the microstructure. Figure 3 shows the effect of HPT straining on microstructural development near the centers of the disks for samples annealed for $1 \mathrm{~h}$ at $800^{\circ} \mathrm{C}$ for (a) the initial annealed unprocessed material and after processing by HPT for (b) $1 / 4$, (c) $1 / 2$, (d) 1 , (e) 5 and (f) 10 turns. Comparing with the initial annealed microstructure, there is very limited grain refinement in the center region after low numbers of turns but significant grain refinement after 5 and 10 turns.

Figures 4 and 5 show EBSD maps of the microstructures of the $\mathrm{Cu}$ samples after HPT and annealing at $400^{\circ} \mathrm{C}$ and $800^{\circ} \mathrm{C}$, respectively. The evolution of the microstructure was examined at three radial positions representing the approximate center, the mid-radius position and near the edge with numbers of turns from 1/4 to 10. With increasing HPT strain, there are some similarities in the development of microstructure at any selected radial position for both 
annealing conditions. In general, grain refinement is much more pronounced near the edge compared to the mid-radius and the center positions. For both annealing conditions, approximate homogeneous grain refinement was achieved at $N \geq 5$ turns at the mid-radius and near edge positions. The microstructures at the centers of the disks demonstrate slow grain refinement with increasing numbers of turns due to the relatively small amounts of strain imposed at the disk centers. At large HPT strains, such as at $N=10$ turns, the microstructure at the disk center continues to have relatively coarse grains after annealing at $400^{\circ} \mathrm{C}$ whereas the microstructure becomes reasonably homogeneous with smaller grain sizes after annealing at $800^{\circ} \mathrm{C}$. Inspection shows that differences in the microstructural development were observed only during the early stages of straining at $N \leq 1$ turn for these two annealing conditions. Figure 5 shows faster grain refinement at the mid-radius and near edge positions for samples annealed at $800^{\circ} \mathrm{C}$ compared to samples annealed at $400^{\circ} \mathrm{C}$. In the early stages of straining, the microstructures at the mid-radius and near edge positions consist of clusters of ultra-fine grains that are present concurrently with relatively coarse recrystallized grains. The faster refinement for samples annealed at $800^{\circ} \mathrm{C}$ is further illustrated at $N=1$ turn where almost complete refinement is visible at the near edge position in Figure 5(i) while coarse grains are present at the near edge position after annealing at $400^{\circ} \mathrm{C}$ in Figure 4(i). At $N \geq 5$ turns, a homogeneous microstructure of ultra-fine grains is visible for both annealing conditions at the mid-radius and near edge positions.

Table 1 shows the average grain sizes measured in the HPT $\mathrm{Cu}$ samples for various positions and numbers of turns. The results show the average grain size is relatively large at the centers of the disks in the early straining up to 1 turn for both annealing conditions. At this stage, the grain size varies between $\sim 6.8$ and $\sim 4.7 \mu \mathrm{m}$ after annealing at $400^{\circ} \mathrm{C}$. The comparable values after annealing at $800^{\circ} \mathrm{C}$ are $\sim 15.7$ and $\sim 8.4 \mu \mathrm{m}$, respectively. At larger HPT strains, such as 
when $N=10$ turns, the grain size is small and within the submicrometer range for both materials. The results also reveal extensive grain refinement under all processing conditions at the midradius and near edge positions. For the disks annealed at $400^{\circ} \mathrm{C}$ the average grain sizes after HPT processing by 1 turn were $\sim 0.44$ and $\sim 0.32 \mu \mathrm{m}$ at the mid-radius and near edge positions; respectively. For the disks annealed at $800^{\circ} \mathrm{C}$, processing by 1 turn gave average grain sizes of $\sim 0.56$ and $\sim 0.47 \mu \mathrm{m}$ at these same two positions. For $N \geq 5$ turns, a homogeneous structure of ultra-fine grains was visible at both the mid-radius and near edge positions and this gave minimum grain sizes at the near edge positions of $\sim 0.28$ and $\sim 0.34 \mu \mathrm{m}$ after annealing at $400^{\circ} \mathrm{C}$ and $800^{\circ} \mathrm{C}$, respectively.

\subsection{Microhardness after the two different annealing conditions}

For both annealing temperatures, the average values of the Vickers microhardness, Hv, were plotted against distance along the radial direction as shown in Figure 6. To obtain a more complete understanding of the effect of the initial annealing temperature on the evolution of hardness after HPT processing, the microhardness values were plotted individually for each separate number of turns. Thus, inspections shows there are similar evolutions in hardness for both annealing temperatures.

At $N=1 / 4$ turn, the hardness increases from $100 \mathrm{Hv}$ at the disk center to a maximum of $\sim 150 \mathrm{Hv}$ at the mid-radius position and then decreases to a minimum of $\sim 80 \mathrm{Hv}$ at the near edge position. This reduction near the outer edge is related to the formation of a mixed structure comprising clusters of ultra-fine grains and coarse recrystallized grains. At $N=1 / 2$ turn, the maximum point of peak hardness is displaced closer to the centers of the disks and there is a large reduction in hardness to $\sim 80 \mathrm{Hv}$ towards the mid-radius position and then an increase in hardness to $\sim 100 \mathrm{Hv}$ at the near edge position. For $N=1 \mathrm{turn}$, the increase in hardness at the near 
edge position becomes even more prominent and approaches a hardness value of $\sim 140 \mathrm{Hv}$. Also, it is important to note that the hardness at the disk center increases only for the disk annealed initially at $800^{\circ} \mathrm{C}$ with a measured increase from $\sim 100 \mathrm{Hv}$ at $N=1 / 4$ turn to $\sim 125 \mathrm{Hv}$ at $N=1$ turn.

An examination of the results in Figure 6(a)-(c) and Figure 4 and 5 shows that the disks annealed at $400^{\circ} \mathrm{C}$ contain higher fractions of recrystallized grains at small HPT strains and this produces a wider range in the hardness drop for $N=1 / 4$ turn. With increasing strain to $N=1$ turn, there is a greater increase in the hardness at the near edge position after annealing at $400^{\circ} \mathrm{C}$. Figure 6(d) shows that the microhardness becomes reasonably homogeneous along the diameter for $N=5$ turns after annealing at $400^{\circ} \mathrm{C}$ except for a small internal circular area with a radius of $\sim 1.0 \mathrm{~mm}$ around the center of the disk where the microhardness values are $\sim 120 \mathrm{Hv}$. The saturation homogeneous microhardness values after this number of turns are $\sim 155 \mathrm{Hv}$ and $\sim 145$ $\mathrm{Hv}$ for samples annealed at $400^{\circ} \mathrm{C}$ and $800^{\circ} \mathrm{C}$, respectively. A similar trend is apparent at $N=10$ turns as shown in Figure 6(e) where essentially complete microhardness homogeneity is achieved along the diameters of both disks with saturation hardness values of $\sim 155 \mathrm{Hv}$ and $\sim 150$ $\mathrm{Hv}$ after annealing at $400^{\circ} \mathrm{C}$ and $800^{\circ} \mathrm{C}$, respectively. In practice, there is a very small circle of lower hardness at $\sim 135 \mathrm{Hv}$ around the center of the disk annealed at $400^{\circ} \mathrm{C}$ but the diameter of this region is only $\sim 0.6 \mathrm{~mm}$.

\section{Discussion}

The results from these experiments reveal an overall similarity in the evolution in microstructure and microhardness after subjecting the $\mathrm{Cu}$ disks to two different annealing conditions. For $N \leq 1$ turn, the microstructures of both samples contain a mixture of coarse recrystallized grains and ultra-fine grains at the mid-radius and near edge positions. The average 
grain sizes at these edge positions are $\sim 0.4 \mu \mathrm{m}$ whereas the average grain sizes at the centers of the disks are larger at $\sim 4.7$ and $\sim 8.4 \mu \mathrm{m}$, respectively. In the early stages of straining, the microhardness values indicate a typical strain hardening as shown in Figure 1(a) and as reported in many pure metals and metallic alloys processed by HPT. However, with increasing HPT strain there is a drop in hardness especially at the mid-radius position. This apparent softening in the microhardness values is consistent with the microstructural development in the early stages of straining where there is a mixture of relatively coarse recrystallized grains and ultra-fine grains at the mid-radius and near edge positions. The softening is due to dynamic recrystallization (DRX) which occurs in high purity $\mathrm{Cu}$ in the very early stages of HPT processing. ${ }^{[38,40]}$ This DRX is a consequence of the adiabatic heating that occurs during the HPT shearing process. ${ }^{[42-46]}$ The results in Figure 6(a) show a significant difference between the two annealed HPT disks at $N=$ $1 / 4$ turn. After annealing at $800^{\circ} \mathrm{C}$ the initial grain size is coarser because of grain growth but there is a clear delay in the onset of softening which occurs at a distance of $\sim 3 \mathrm{~mm}$ from the disk center compared with a distance of $\sim 1.5 \mathrm{~mm}$ from the center after annealing at $400^{\circ} \mathrm{C}$. This is consistent with earlier data for high purity and ultra-high purity austenitic stainless steels after deformation by uniaxial compression where the larger initial grain sizes also led to a clear delay in the onset of softening due to DRX. ${ }^{[47]}$ This delay is due to the lower fraction of grain boundaries in the alloy with the larger initial grain size.

A recent study on the evolution of the microstructure and microhardness of OFHC $\mathrm{Cu}$ showed that there was softening in the early stages of straining due to self-annealing ${ }^{[39]}$ although the softening was not present after storing the HPT disks for $48 \mathrm{~h}$ at RT. The behavior was shown to correspond to a typical hardening without recovery as occurs in most metals and alloys where the hardness is low near the center and increases gradually to a saturation value. However, 
after storing for longer periods of up to 6 weeks the HPT $\mathrm{Cu}$ disks showed a clear softening similar to that presented in Figure 6.

The current results also demonstrate the occurrence of self-annealing in the early stages of straining. Such softening is believed to be associated with an abnormal grain growth. The accumulation of high dislocation densities in the very early stages of straining lead to strain hardening. This is followed by a self-annealing effect as recrystallization and grain growth occur leading to a delayed recovery associated with dislocation annihilation. With increasing strain, the microstructure became homogeneous and consists of an array of ultra-fine grains that give strain hardening followed by hardness saturation. Many reports on copper and other materials show the potential for the occurrence of self-annealing after processing by SPD techniques and storing at room temperature for long periods. For example, experiments on $\mathrm{Cu}$ disks processed by HPT and stored for $100 \mathrm{~h}$ at RT showed a decrease in hardness due to self-annealing ${ }^{[48]}$ and samples of copper $^{[49]}$ and single crystal copper ${ }^{[50]}$ showed the occurrence of recrystallization after processing by ECAP and subsequent storage at RT for periods of 8 years and 2 months, respectively. In addition, high purity Ag showed a decrease in hardness after processing by ECAP and storage at RT for periods up to 4 months. ${ }^{[51]}$ A recent study on a Pb-62\% Sn alloy processed by HPT and stored for periods up to 11 days at RT showed grain coarsening at the disc edge due to selfannealing. ${ }^{[52]}$ As noted earlier, the microstructure and microhardness results in this investigation were obtained after room temperature storage of the HPT-processed disks for a period of 6 months and this suggests the softening is due to self-annealing rather than DRX.

Further straining to a relatively large number of turns (5 and 10 turns) led to an approximately total homogeneous microstructure in the $\mathrm{Cu}$ disks initially annealed at $800^{\circ} \mathrm{C}$ except for a very small diameter of $\sim 100 \mu \mathrm{m}$ at the center of the disk processed through 5 turns 
where there were coarser grains. This homogeneity is visible both in the EBSD micrographs in Figures $5(\mathrm{j}-\mathrm{o})$ and in the straight line along the diameter in the microhardness plots in Figures 6(d and e). The result is consistent with earlier observations reported for OFHC $\mathrm{Cu}$ initially annealed at $400^{\circ} \mathrm{C}$ where there was a homogeneous microhardness along the diameters after HPT for 5 and 10 turns and RT storage for periods between $48 \mathrm{~h}$ and 6 weeks. ${ }^{[39]}$ Nevertheless, the material initially annealed at $400^{\circ} \mathrm{C}$ in the present study exhibited lower microhardness values near the centers of the disks after HPT for 5 and 10 turns. The microstructures at the center positions of these disks consisted of relatively large grains with average grain sizes of $\sim 1.52$ and $\sim 0.97 \mu \mathrm{m}$ after HPT for 5 and 10 turns, respectively. These measurements show that the area of lower microhardness becomes smaller in the disk processed for 10 turns.

In order to investigate the differences in the hardness evolution in the high purity $\mathrm{Cu}$ initially annealed at these two temperatures, corresponding to $\sim 0.5 T_{\mathrm{m}}$ and $\sim 0.8 T_{\mathrm{m}}$, respectively, the microhardness measurements were plotted against the equivalent von Mises strain as calculated using eq. (1). This result is shown in Figure 7 where the equivalent strain is plotted for both annealing temperatures on $(a, c)$ a normal scale and $(b, d)$ a logarithmic scale in order to provide better demonstrations of the experimental data. Both materials show the same effect of hardening and then softening in the early stages of straining and this is followed by hardening again up to similar hardness values above $\sim 150 \mathrm{Hv}$. There is a delay in the onset of softening for the $\mathrm{Cu}$ disks initially annealed at $800^{\circ} \mathrm{C}$. As shown in Figure $7(\mathrm{~b})$, the $\mathrm{Cu}$ disks annealed at $400^{\circ} \mathrm{C}$ experience hardening up to a strain of $\sim 2$ and then softening at strains between $\sim 3$ and $\sim 8$ and thereafter a hardening to a homogeneous microhardness value at a strain of $\sim 22$. By contrast, the $\mathrm{Cu}$ disks annealed at $800^{\circ} \mathrm{C}$ as shown in Figure $7(\mathrm{~d})$ experience hardening up to a strain of $\sim 3.5$, then softening at strains between $\sim 5$ and $\sim 10$ followed by later hardening again to a 
homogeneous microhardness value at $\sim 22$. The delay in the onset of softening in the latter material is due to the larger initial grain sizes in the disks annealed at the higher temperature of $\sim 0.8 T_{\mathrm{m}}$.

Three models for the evolution of microhardness with increasing equivalent strain were proposed earlier ${ }^{[37]}$ and then developed in detail in an extensive review of experimental data. ${ }^{[30]}$ These three models were illustrated earlier in Figure 1. The first model in Figure 1(a) shows conventional behavior of microhardness evolution where there is strain hardening without recovery and then a saturation microhardness value. This latter model has been reported in many different metals and alloys. ${ }^{[30]}$ In the second model, the strain hardens rapidly in the early stages of straining, then softens with rapid recovery to reach a lower saturation microhardness value. This model applies to some high purity metals such as $\mathrm{Al},{ }^{[1-33]} \mathrm{Mg}^{[35]}$ and $\mathrm{Zn} .{ }^{[34]}$ As shown in Figure 1( $a$ and $b)$, both of these models have final saturation microhardness values which lie above the annealed or as-received values. Finally, the third model illustrated in Figure 1(c) shows a significant strain weakening but ultimately a saturation microhardness that lies below the annealed microhardness value. This model applies to alloys such as $\mathrm{Zn}-\mathrm{Al}$ and $\mathrm{Pb}-\mathrm{Sn}{ }^{[36]}$ The results of the present study on high purity OFHC $\mathrm{Cu}$ suggest a different evolution of microhardness with increasing equivalent strain wherein the strain hardens rapidly and then softens due to self-annealing but with further hardening again to reach a new saturation microhardness value that lies above the annealed value. A similar hardness-strain behavior was illustrated previously when high purity copper (99.99\%) disks were processed by HPT at room temperature for $N=1$ and 12 turns and then subjected to post-annealing at $433 \mathrm{~K}$ and $513 \mathrm{~K}$ for 2 h. ${ }^{[53]}$ These two independent experimental studies, which are in excellent agreement, provide good information about the microstructural evolution in severely deformed $\mathrm{Cu}$ in the early stages 
of straining. Further experiments are now needed to investigate the possible extension of this new microhardness model to other high purity metals.

\section{Conclusions}

1. High-purity $\mathrm{OFHC} \mathrm{Cu}$ disks were prepared under two different annealing temperatures, 400 and $800^{\circ} \mathrm{C}$ equivalent to $\sim 0.5 T_{\mathrm{m}}$ and $\sim 0.8 T_{\mathrm{m}}$, respectively, and then they were processed by HPT at room temperature for $1 / 4,1 / 2,1,5$ and 10 turns.

2. The results show a similarity in the evolution of the microstructure and microhardness for both annealing conditions. In the early stages of straining, for $N \leq 1$, selfannealing occurs concurrently with grain refinement at the mid-radius and near edge positions. Full grain refinement is observed at large strains and homogeneous microstructures are achieved after 10 turns. The microstructure was also homogeneous after 5 turns except for a small area around the center of the disk after initially annealing at $400^{\circ} \mathrm{C}$.

3. A delay in the onset of softening was recorded in the material initially annealed at $800^{\circ} \mathrm{C}$ due to the relatively larger initial average grain size.

4. A new model of hardness evolution with equivalent strain is proposed for OFHC high-purity $\mathrm{Cu}$. In this model, the hardness initially exhibits rapid hardening, then softening due to self-annealing, followed by further hardening to reach a homogeneous saturation hardness that is higher than in the initially annealed condition. 


\section{References:}

1. A. P. Zhilyaev, T. G. Langdon, Prog. Mater. Sci. 2008, 53, 893.

2. A. P. Zhilyaev, G. V. Nurislamova, B.-K. Kim, M. D. Baró, J. A. Szpunar, T. G. Langdon, Acta Mater. 2003, 51, 753.

3. D. C. Patil, S. A. Kori, K. Venkateswarlu, G. Das, S. N. Alhajeri, T. G. Langdon, J. Mater. Sci. 2013, 48, 4773.

4. J. Wongsa-Ngam, M. Kawasaki, T. G. Langdon, J. Mater. Sci. 2013, 48, 4653.

5. R. Z. Valiev, Y. V. Ivanisenko, E. F. Rauch, B. Baudelet, Acta Mater. 1996, 44, 4705.

6. F. Wetscher, A. Vorhauer, R. Stock, R. Pippan, Mater. Sci. Eng. A 2004, 387-389, 809.

7. Y. Estrin, A. Molotnikov, C. H. J. Davies, R. Lapovok, J. Mech. Phys. Solids 2008, 56, 1186.

8. A. Loucif, R. B. Figueiredo, T. Baudin, F. Brisset, T. G. Langdon, Mater. Sci. Eng. A 2010, 527, 4864.

9. S. N. Alhajeri, M. Kawasaki, N. Gao, T. G. Langdon, Mater. Sci. Forum 2011, 667-669, 277.

10. M. Kawasaki, S. N. Alhajeri, C. Xu, T. G. Langdon, Mater. Sci. Eng. A 2011, 529, 345.

11. M. Ashida, Z. Horita, T. Kita, A. Kato, Mater. Trans. 2012, 53, 13.

12. T. Mungole, N. Nadammal, K. Dawra, P. Kumar, M. Kawasaki, T. G. Langdon, J. Mater. Sci. 2013, 48, 4671.

13. S. N. Alhajeri, K. J. Al-Fadhalah, A. I. Almazrouee, T. G. Langdon, Mater. Charact. 2016, 118, 270.

14. Y. Z. Tian, S. D. Wu, Z. F. Zhang, R. B. Figueiredo, N. Gao, T. G. Langdon, Acta Mater. 2011, 59, 2783.

15. K. Edalati, Z. Horita, T. Furuta, S. Kuramoto, Mater. Sci. Eng. A 2013, 559, 506.

16. A. Y. Khereddine, F. H. Larbi, M. Kawasaki, T. Baudin, D. Bradai, T. G. Langdon, Mater. Sci. Eng. A 2013, 576, 149.

17. Y. C. Wang, T. G. Langdon, Mater. Sci. Eng. A 2013, 559, 861.

18. K. Edalati, J. Matsuda, H. Iwaoka, S. Toh, E. Akiba, Z. Horita, Int. J. Hydrogen Energy 2013, 38, 4622 .

19. H. Shahmir, P. H. R. Pereira, Y. Huang, T. G. Langdon, Mater. Sci. Eng. A 2016, 669, 358. 
20. J. Bai, F. Xue, S. N. Alhajeri, T. G. Langdon, Mater. Sci. Forum 2011, 667-669, 391.

21. P. Serre, R. B. Figueiredo, N. Gao, T. G. Langdon, Mater. Sci. Eng. A 2011, 528, 3601.

22. A. Al-Zubaydi, R. B. Figueiredo, Y. Huang, T. G. Langdon, J. Mater. Sci. 2013, 48, 4661.

23. S. A. Torbati-Sarraf, S. Sabbaghianrad, R. B. Figueiredo, T. G. Langdon, J. Alloys Compds. 2017, 712, 185.

24. F. Wetscher, B. Tian, R. Stock, R. Pippan, Mater. Sci. Forum 2006, 503-504, 455.

25. K. Edalati, T. Fujioka, Z. Horita, Mater. Trans. 2009, 50, 44.

26. D. M. Marulanda Cardona, J. Wongsa-Ngam, T. G. Langdon, J. Mater. Res. Technol. 2014, 3, 344 .

27. S. Ni, Y. B. Wang, X. Z. Liao, S. N. Alhajeri, H. Q. Li, Y. H. Zhao, E. J. Lavernia, S. P. Ringer, T. G. Langdon, Y. T. Zhu, Mater. Sci. Eng. A 2011, 528, 3398.

28. K. Edalati, T. Daio, Z. Horita, K. Kishida, H. Inui, J. Alloy Compds. 2013, 563, 221.

29. K. Edalati, Z. Horita, Mater. Trans. 2010, 51, 1051.

30. M. Kawasaki, J. Mater. Sci. 2014, 49, 18.

31. C. Xu, Z. Horita, T. G. Langdon, Acta Mater. 2007, 55, 203.

32. C. Xu, Z. Horita, T. G. Langdon, Mater. Trans. 2010, 51, 2.

33. M. Kawasaki, R. B. Figueiredo, T. G. Langdon, Acta Mater. 2011, 59, 308.

34. K. Edalati, Z. Horita, Mater. Sci. Eng. A 2011, 528, 7514.

35. K. Edalati, A. Yamamoto, Z. Horita, T. Ishihara, Scripta Mater. 2011, 64, 880.

36. N. Zhang, M. Kawasaki, Y. Huang, T. G. Langdon, J. Mater. Sci. 2013, 48, 4582.

37. M. Kawasaki, B. Ahn, T. G. Langdon, Mater. Sci. Eng. A 2010, 527, 7008.

38. A. I. Almazrouee, K. J. Al-Fadhalah, S. N. Alhajeri, T. G. Langdon, Mater. Sci. Eng. A 2015, 641, 21.

39. Y. Huang, S. Sabbaghianrad, A. I. Almazrouee, K. J. Al-Fadhalah, S. N. Alhajeri, T. G. Langdon, Mater. Sci. Eng. A 2016, 656, 55.

40. K. J. Al-Fadhalah, S. N. Alhajeri, A. I. Almazrouee, T. G. Langdon, J. Mater. Sci. 2013, $48,4563$.

41. R. B. Figueiredo, P. H. R. Pereira, M. T. P. Aguilar, P. R. Cetlin, T. G. Langdon, Acta Mater. 2012, 60, 3190.

42. D. Yamaguchi, Z. Horita, M. Nemoto, T. G. Langdon, Scripta Mater. 1999, 41, 791. 
43. A. P. Zhilyaev, J. M. García-Infanta, F. Carreño, T. G. Langdon, O. A. Ruano, Scripta Mater. 2007, 57, 763.

44. Y. Todaka, M. Umemoto, A. Yamazaki, J. Sasaki, K. Tsuchiya, Mater. Trans. 2008, 49, 47.

45. A. P. Zhilyaev, S. Swaminathan, A. I. Pshenichnyuk, T. G. Langdon, T. R. McNelley, J. Mater. Sci. 2013, 48, 4626.

46. P. H. R. Pereira, R. B. Figueiredo, Y. Huang, P. R. Cetlin, T. G. Langdon, Mater. Sci. Eng. A 2014, 593, 185.

47. M. El Wahabi, L. Gavard, F. Montheillet, J. M. Cabrera, J. M. Prado, Acta Mater. 2005, $53,4605$.

48. A. P. Zhilyaev, T. G. Langdon, J. Mater. Sci. 2014, 49, 6529.

49. O. V. Mishin, A. Godfrey, Metall. Mater. Trans. 2008, A39, 2923.

50. G. Wang, S. D. Wu, L. Zuo, C. Esling, Z. G. Wang, G. Y. Li, Mater. Sci. Eng, A 2003, $346,83$.

51. J. Gubicza, N. Q. Chinh, J. L. Lábár, Z. Hegedüs, P. Szommer, G. Tichy, T. G. Langdon, J. Mater. Sci. 2008, 43, 5672.

52. Y. Huang, S. Sabbaghianrad, A. I. Almazrouee, K. J. Al-Fadhalah, S. N. Alhajeri, N. Zhang, T. G. Langdon, J. Mater. Res. Technol. 2017, submitted for publication.

53. K. Edalati, K. Imamura, T. Kiss, Z. Horita, Mater. Trans. 2012, 53, 123. 


\section{Figure captions}

Fig. 1. Schematic illustration of three models of variation of hardness with equivalent strain for metals processed by HPT: (a) hardening without recovery, (b) softening with rapid recovery and (c) weakening. ${ }^{[37]}$

Fig. 2. Optical Micrographs of annealed OFHC Cu samples at: (a-b) $0.5 \mathrm{~T}$, (c-d) $0.8 \mathrm{~T}_{\mathrm{m}}$.

Fig. 3. Optical Micrographs at the center of HPT Cu disks that were initially annealed at $0.8 \mathrm{~T}_{\mathrm{m}}$ : (a) unprocessed disk, and disks HPT processed for different turns: (b) 1/4, (c) 1/2, (d) 1, (e) 5 and (f) 10 turns.

Fig. 4. EBSD maps of the microstructures of $\mathrm{Cu}$ disks processed by HPT after annealing at 400 ${ }^{\circ} \mathrm{C}:(\mathrm{a}-\mathrm{c}) 1 / 4,(\mathrm{~d}-\mathrm{f}) 1 / 2,(\mathrm{~g}-\mathrm{i}) 1,(\mathrm{j}-\mathrm{l}) 5$ and $(\mathrm{m}-\mathrm{o}) 10$ turns.

Fig. 5. EBSD maps of the microstructures of $\mathrm{Cu}$ disks processed by HPT after annealing at 800 ${ }^{\circ} \mathrm{C}:(\mathrm{a}-\mathrm{c}) 1 / 4,(\mathrm{~d}-\mathrm{f}) 1 / 2,(\mathrm{~g}-\mathrm{i}) 1,(\mathrm{j}-\mathrm{l}) 5$ and $(\mathrm{m}-\mathrm{o}) 10$ turns.

Fig. 6. Average microhardness measurements, $\mathrm{Hv}$, recorded along the diameters of $\mathrm{Cu}$ disks annealed at $400{ }^{\circ} \mathrm{C}$ and $800{ }^{\circ} \mathrm{C}$ that were subjected to HPT for: (a) $1 / 4$, (b) $1 / 2$, (c) 1 , (d) 5 and (e) 10 turns.

Fig. 7. Average Vickers microhardness plotted against equivalent strain for HPT Cu disks. Plots of $\mathrm{Cu}$ samples initially annealed at $400{ }^{\circ} \mathrm{C}$ using: (a) linear scale, (b) logarithmic scale. Plots of $\mathrm{Cu}$ samples initially annealed at $800{ }^{\circ} \mathrm{C}$ using: (c) linear scale, (d) logarithmic scale.

\section{Table captions}

Table 1. Measured average grain size of HPT Cu samples. 


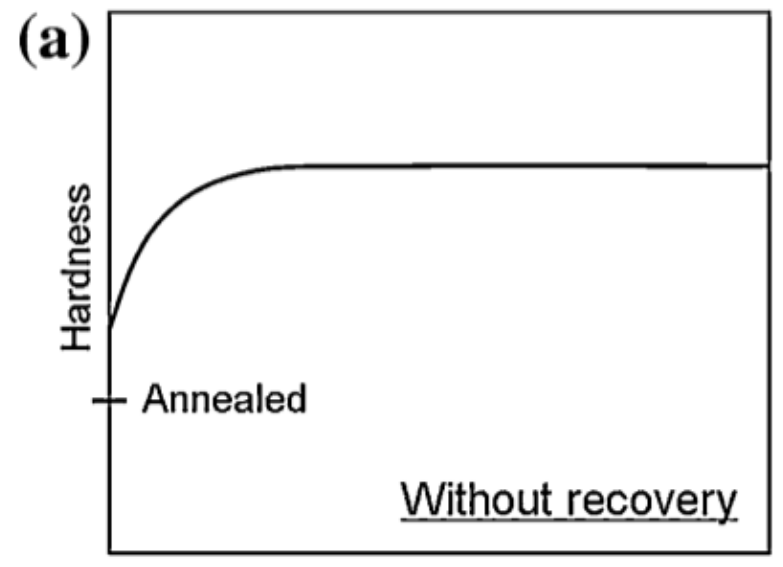

Equivalent strain

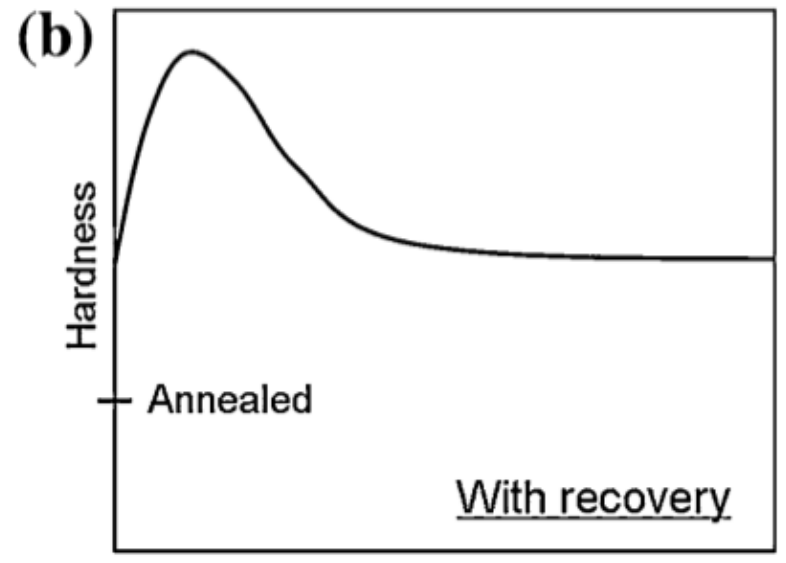

Equivalent strain

(c)

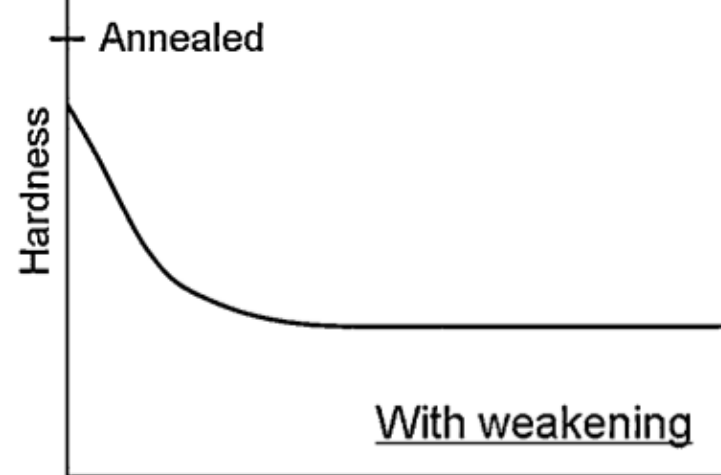

Equivalent strain

Fig. 1. Schematic illustration of three models of variation of hardness with equivalent strain for metals processed by HPT: (a) hardening without recovery, (b) softening with rapid recovery, and (c) weakening. ${ }^{[37]}$ 

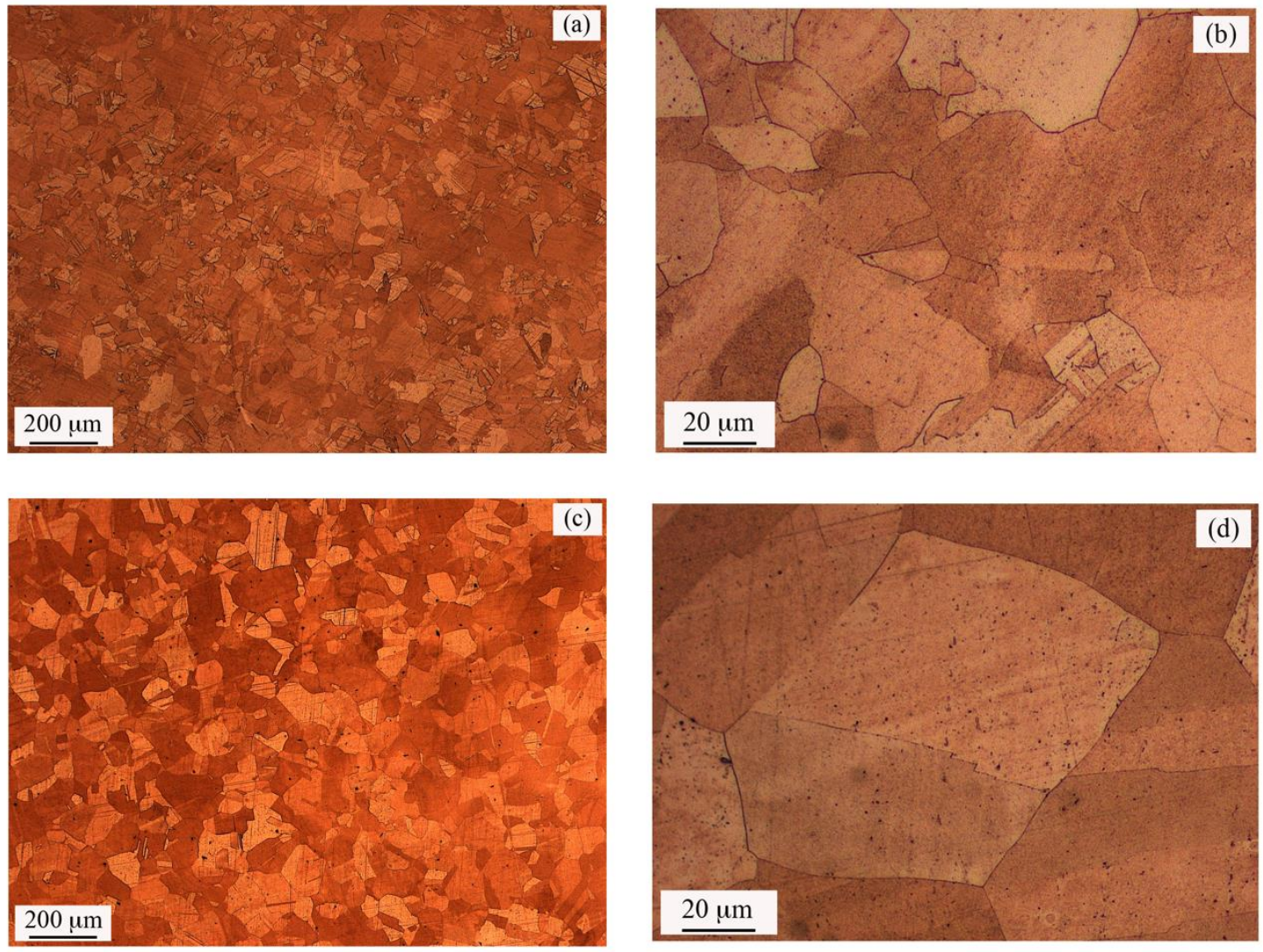

Fig. 2. Optical Micrographs of annealed OFHC Cu samples at: (a-b) $0.5 \mathrm{~T}_{\mathrm{m}}$, (c-d) $0.8 \mathrm{~T}_{\mathrm{m}}$. 


\section{OFHC Cu Annealed at $800 \mathrm{C}$}

HPT: 6 GPa, RT
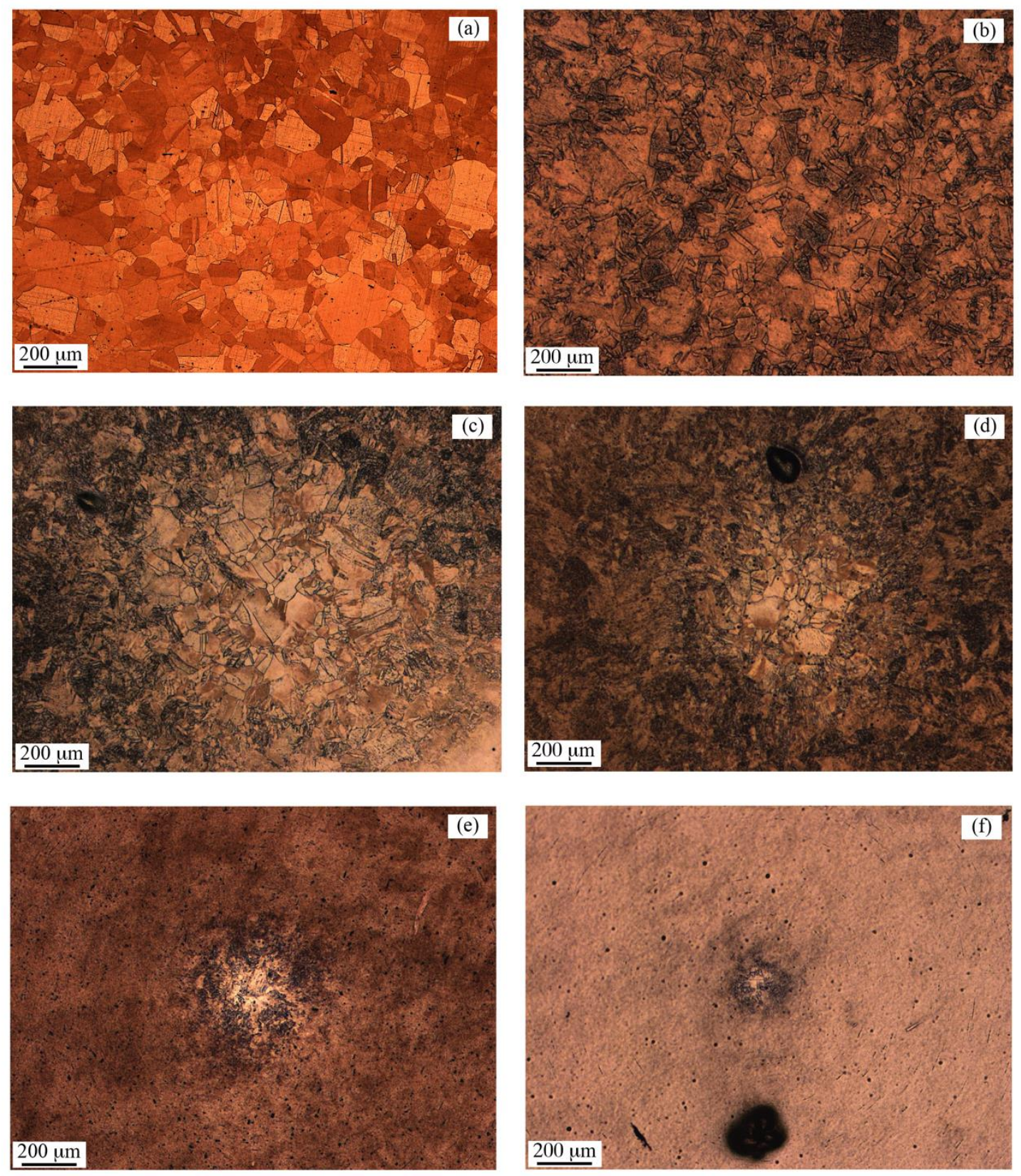

Fig. 3. Optical Micrographs at the center of HPT Cu disks that were initially annealed at $0.8 \mathrm{Tm}$ : (a) unprocessed disk, and disks HPT processed at different turns: (b) 1/4, (c) 1/2, (d) 1, (e) 5 and (f) 10 turns. 


\section{OFHC Cu Annealed at $400 \mathrm{C}$}

\section{HPT: $6 \mathrm{GPa}, \mathrm{RT}$}
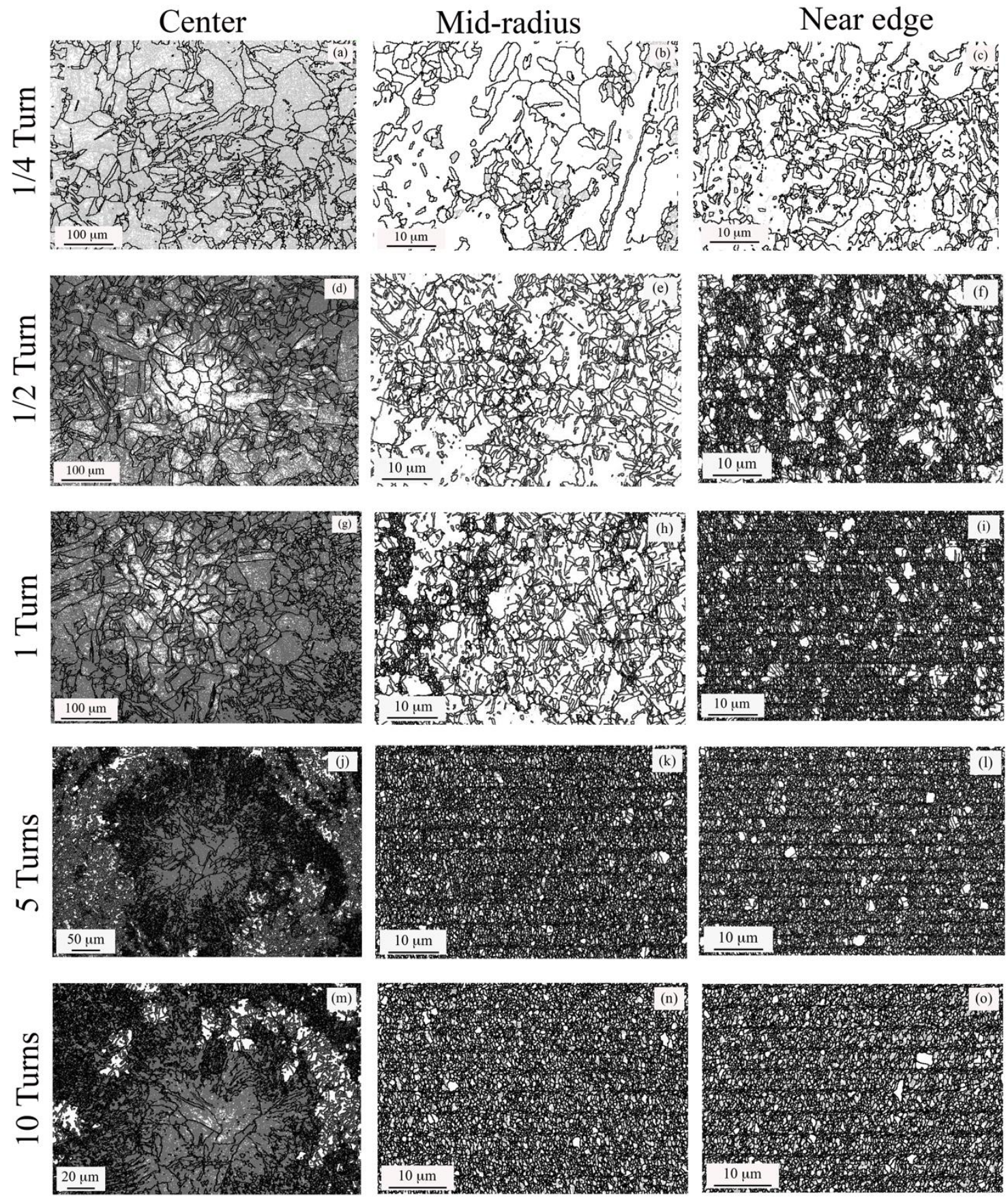

Fig. 4. EBSD maps of the microstructures of $\mathrm{Cu}$ disks processed by HPT after annealing at 400 ${ }^{\circ} \mathrm{C}:(\mathrm{a}-\mathrm{c}) \mathrm{1} / 4,(\mathrm{~d}-\mathrm{f}) 1 / 2,(\mathrm{~g}-\mathrm{i}) 1,(\mathrm{j}-\mathrm{l}) 5$ and $(\mathrm{m}-\mathrm{o}) 10$ turns. 


\section{OFHC $\mathrm{Cu}$ Annealed at $800 \mathrm{C}$}

HPT: $6 \mathrm{GPa}$, RT
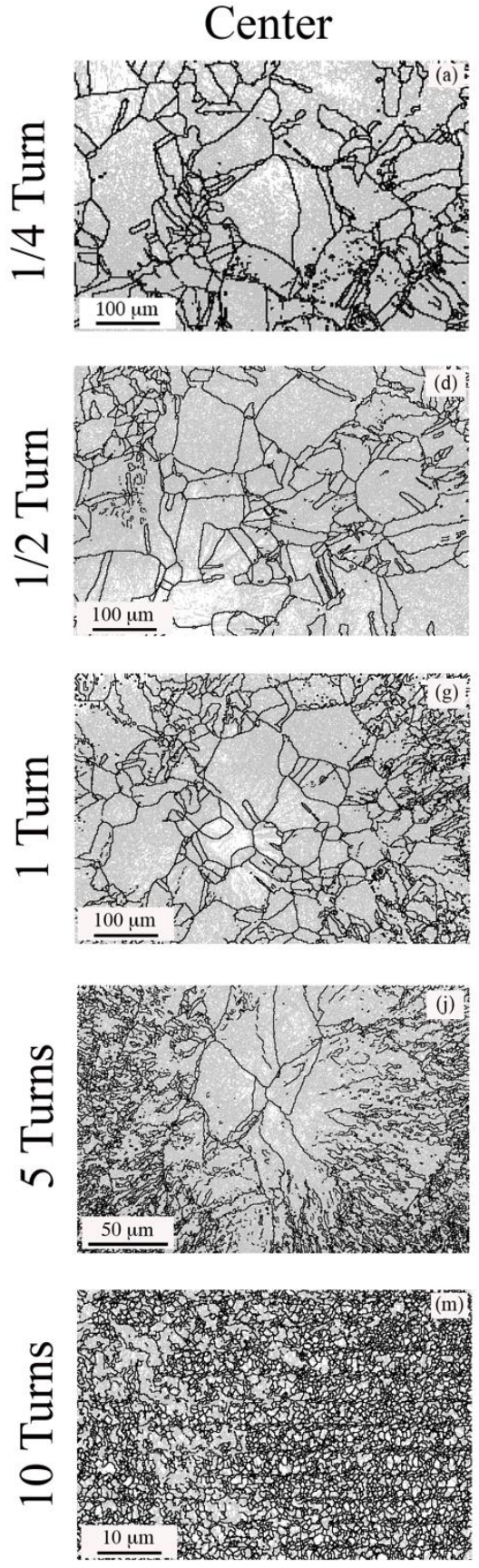
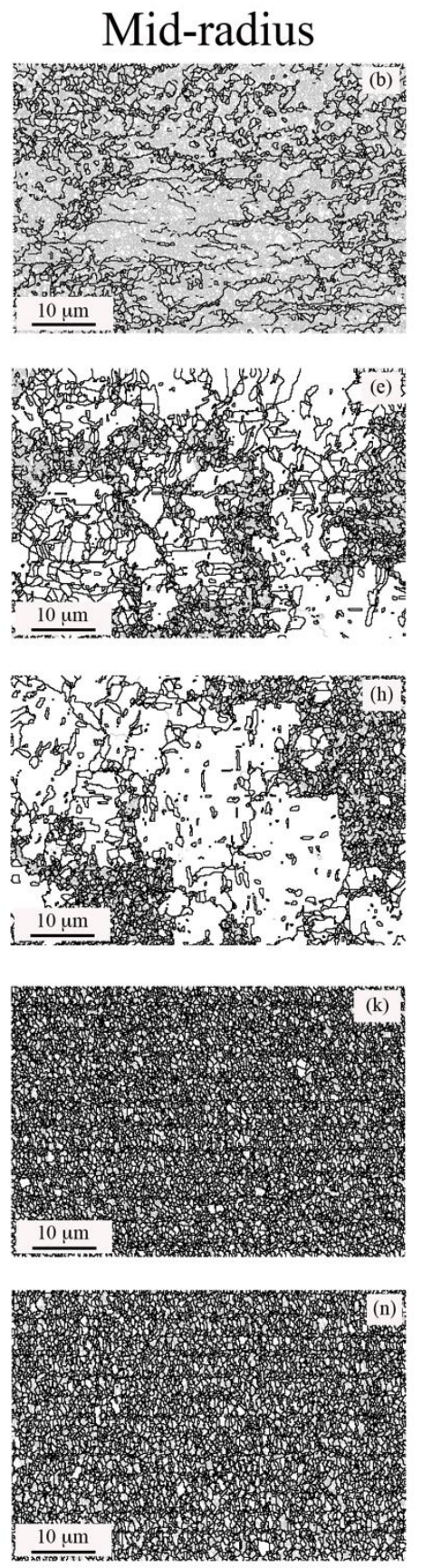
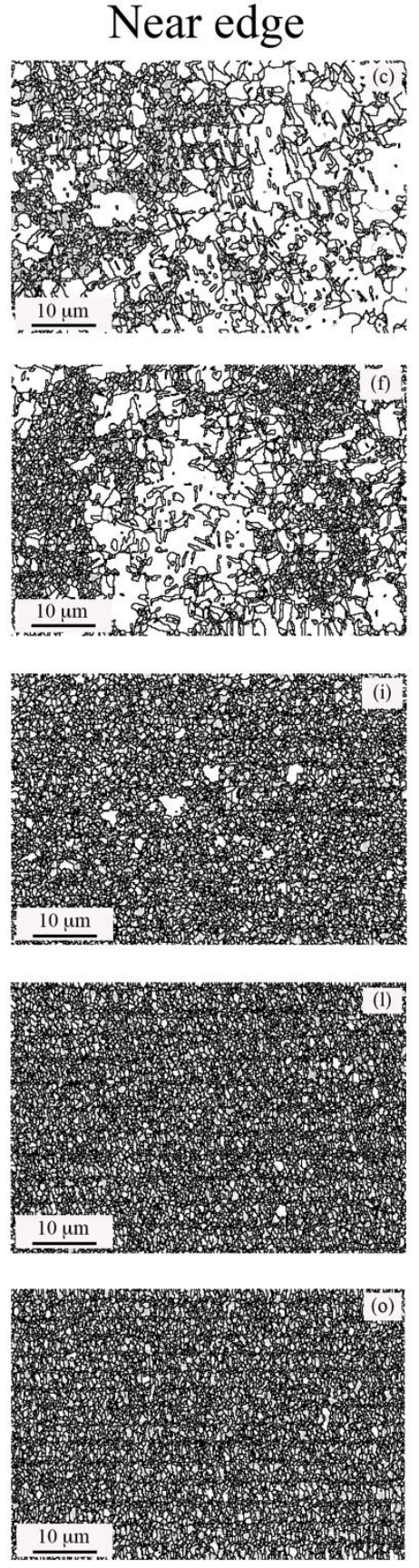

Fig. 5. EBSD maps of the microstructures of $\mathrm{Cu}$ disks processed by HPT after annealing at 800 
${ }^{\circ} \mathrm{C}:(\mathrm{a}-\mathrm{c}) 1 / 4,(\mathrm{~d}-\mathrm{f}) 1 / 2,(\mathrm{~g}-\mathrm{i}) 1,(\mathrm{j}-\mathrm{l}) 5$ and $(\mathrm{m}-\mathrm{o}) 10$ turns.

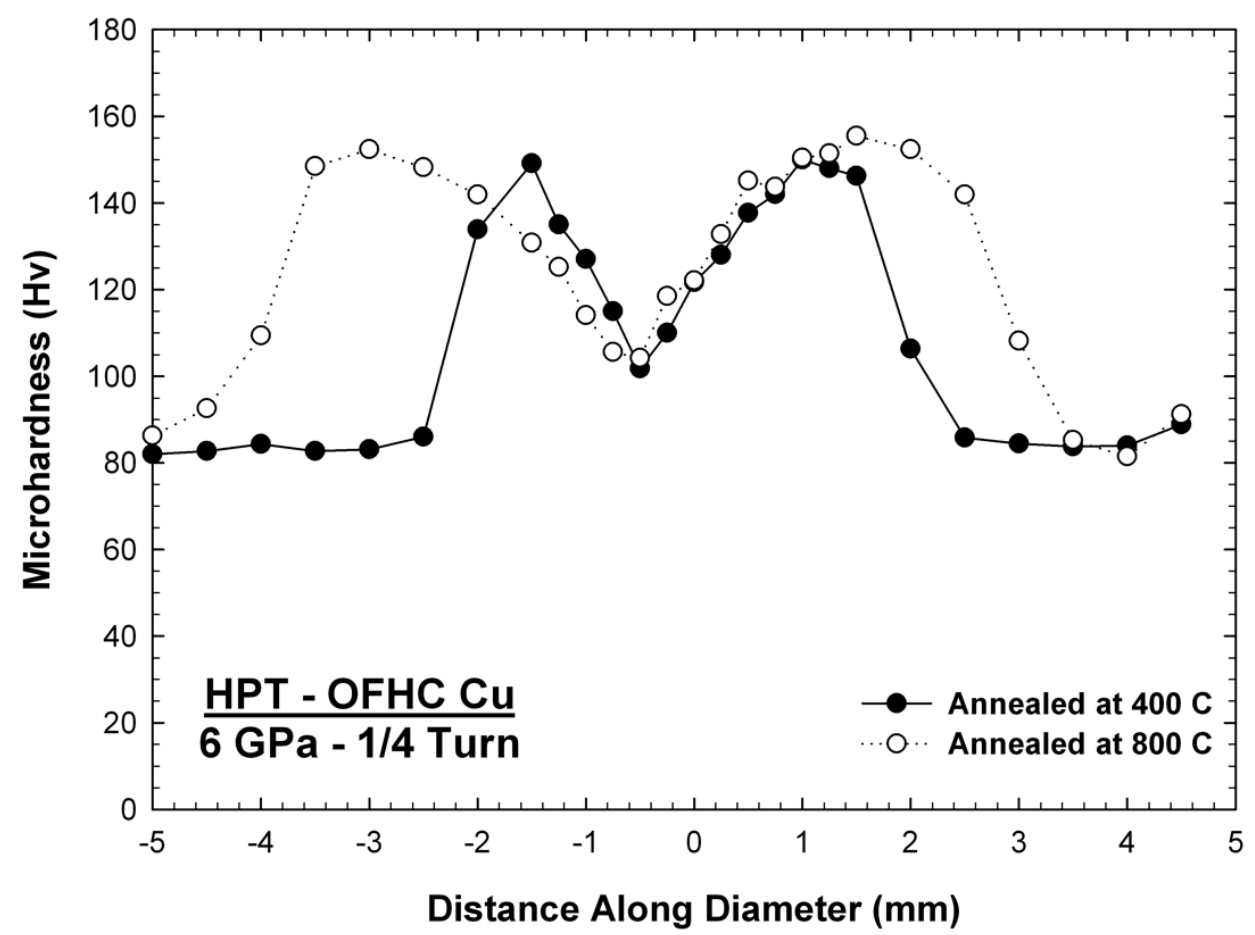

(a)

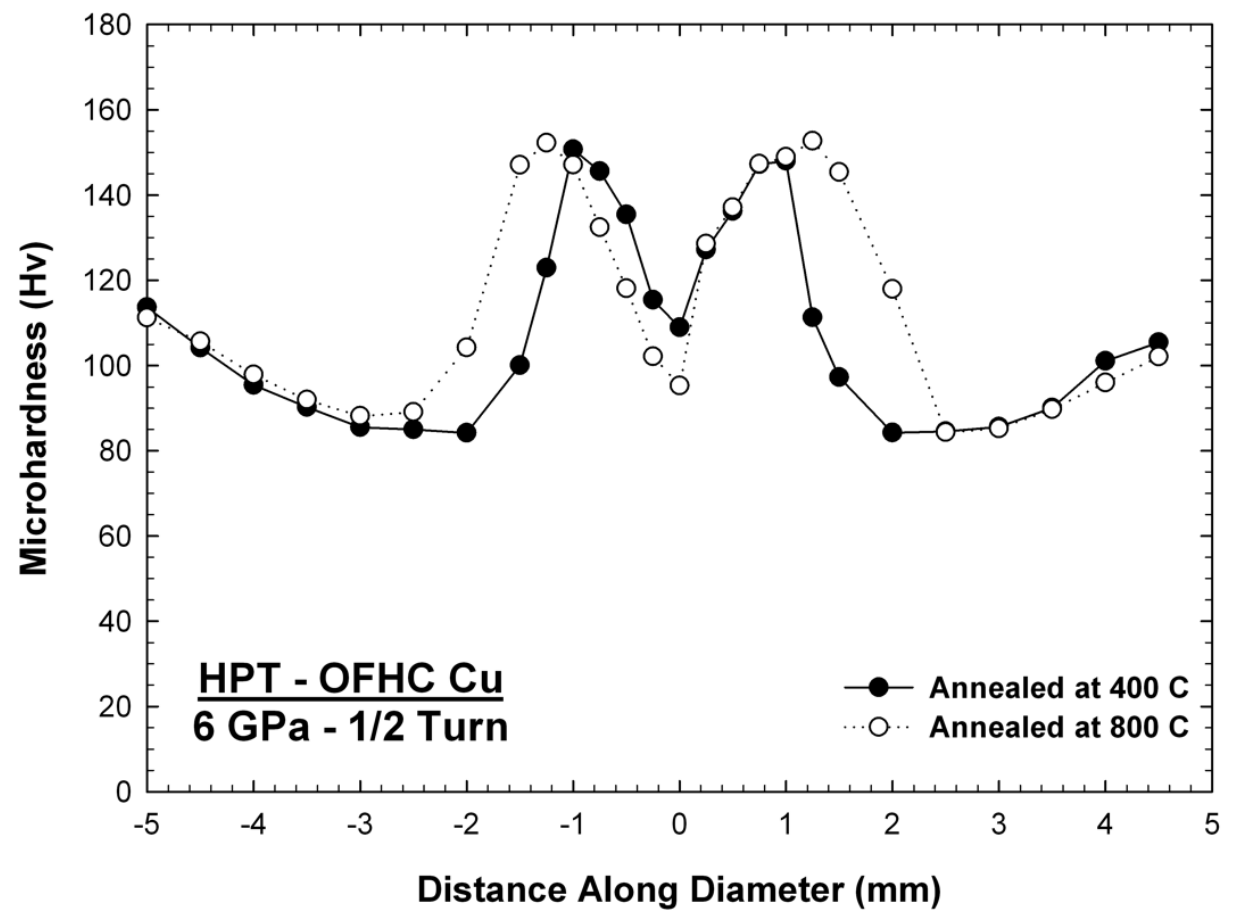


(b)

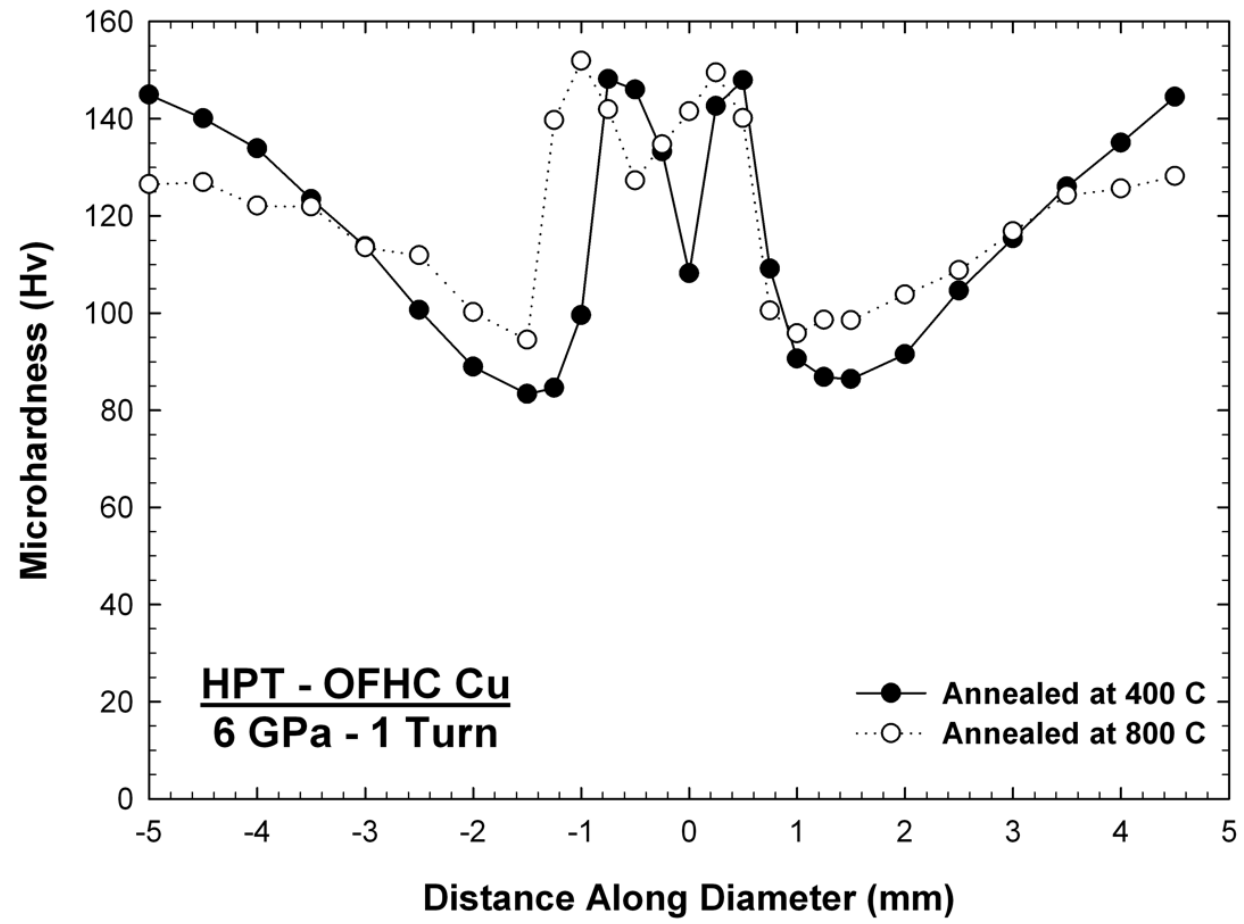

(c)

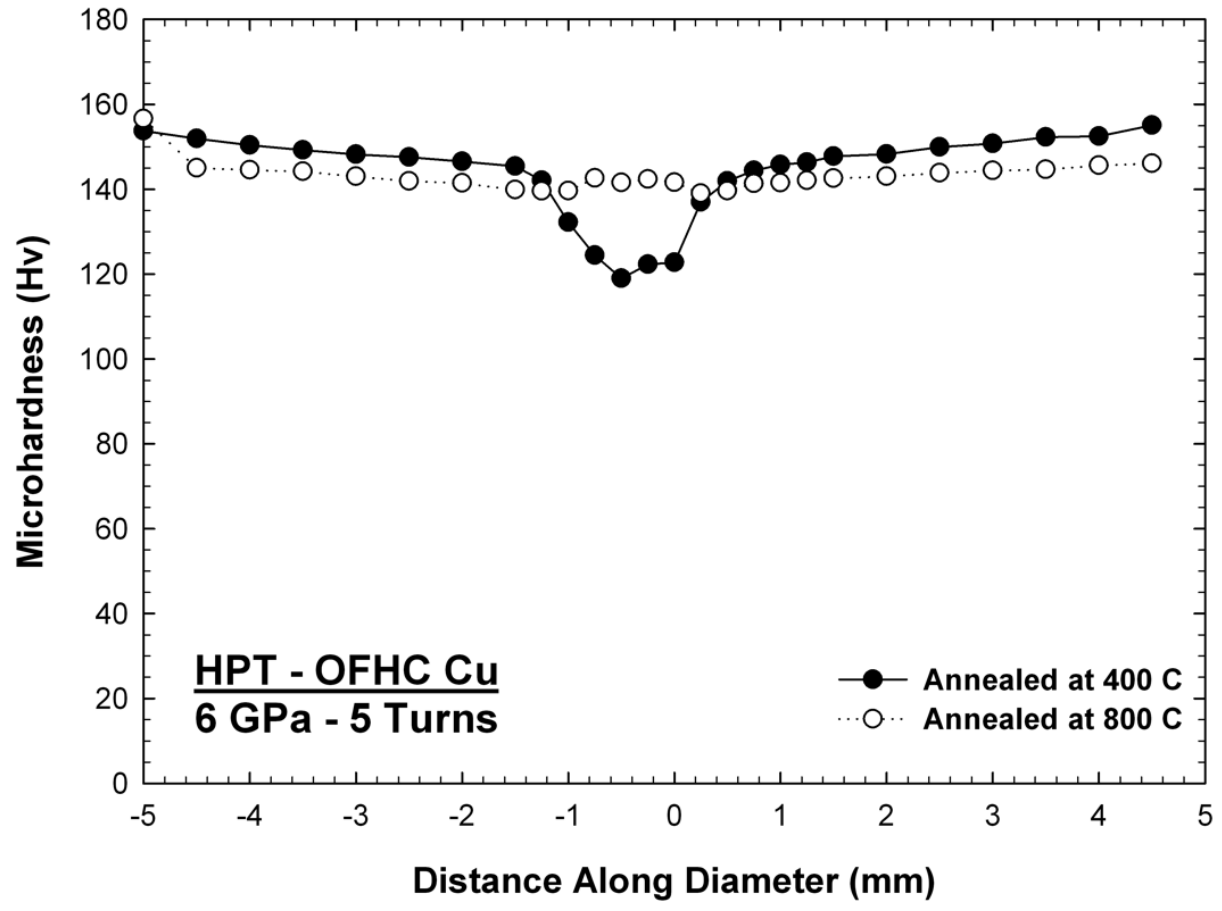


(d)

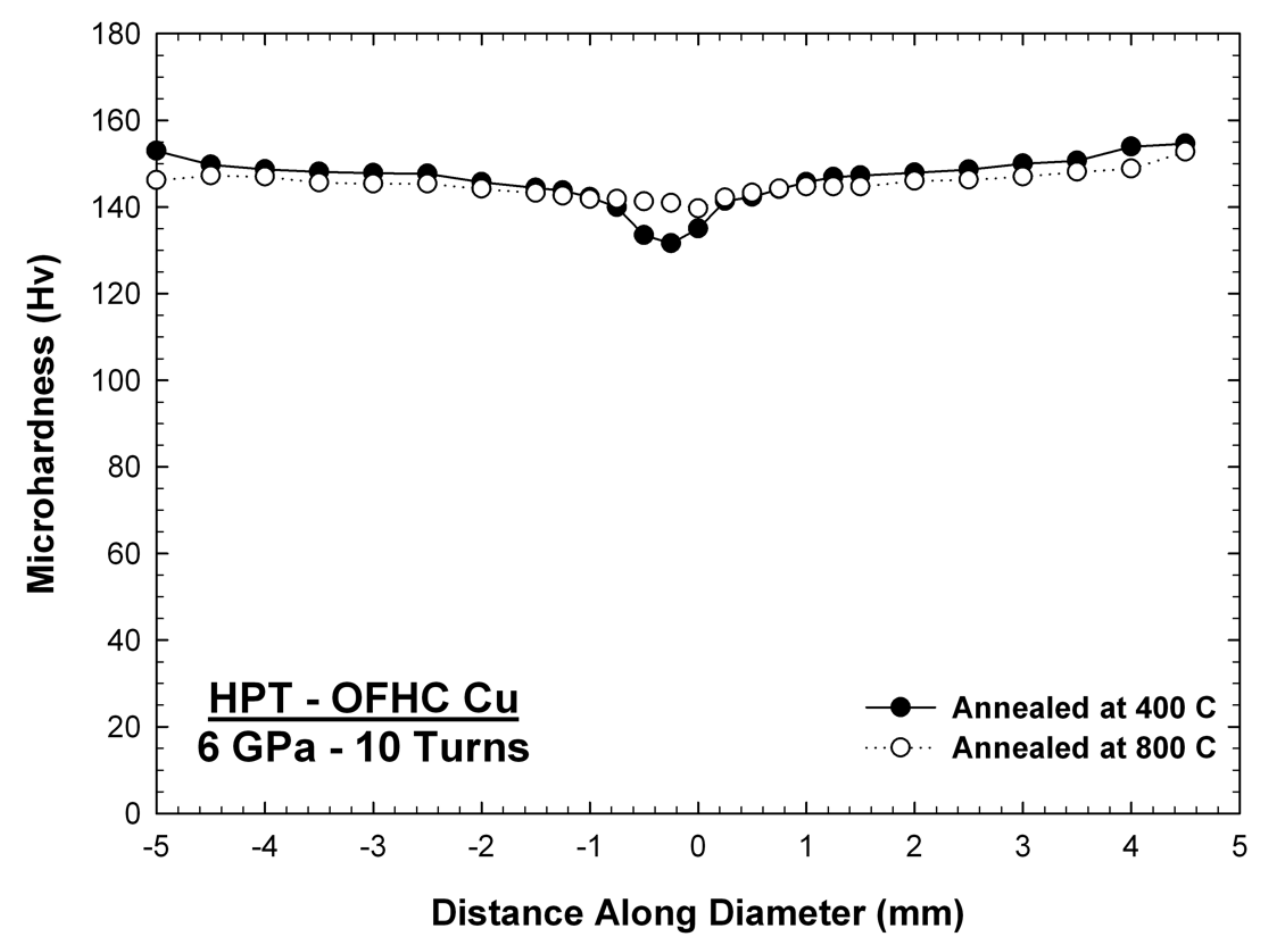

(e)

Fig. 6. Average microhardness measurements, $\mathrm{Hv}$, recorded along the diameter of $\mathrm{Cu}$ disks annealed at $400{ }^{\circ} \mathrm{C}$ and $800{ }^{\circ} \mathrm{C}$ that were subjected to HPT for: (a) $1 / 4$, (b) $1 / 2$, (c) 1 , (d) 5 and (e) 10 turns. 


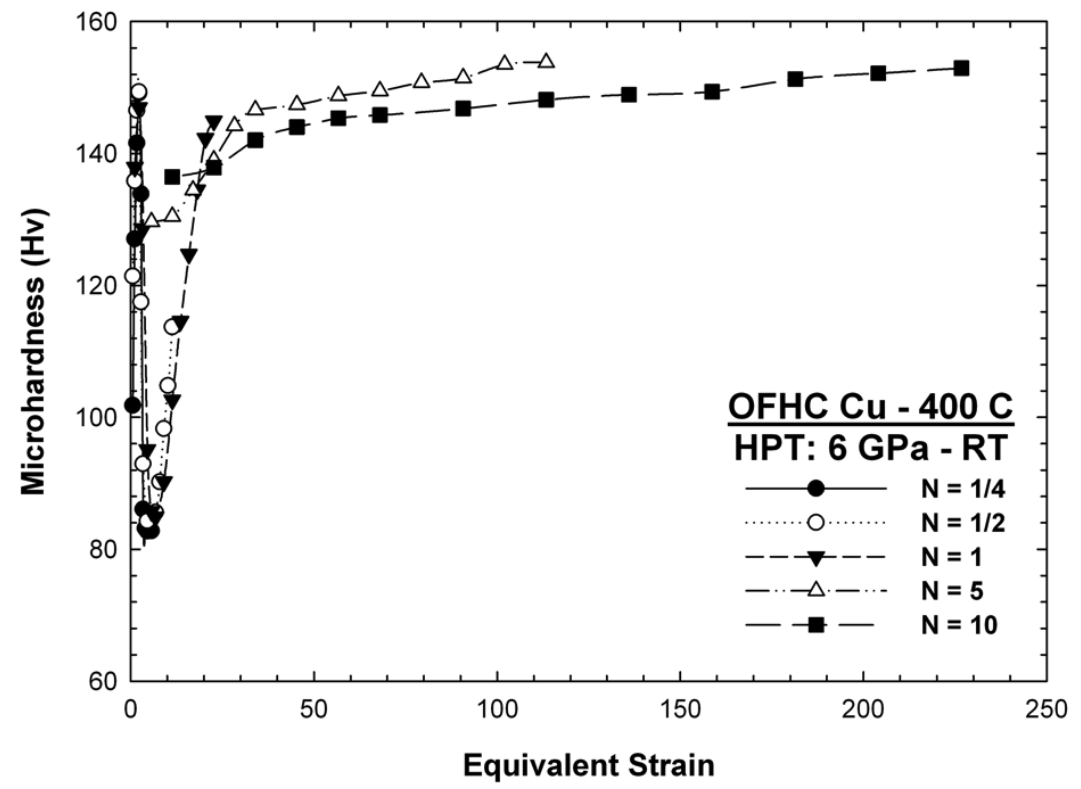

(a)

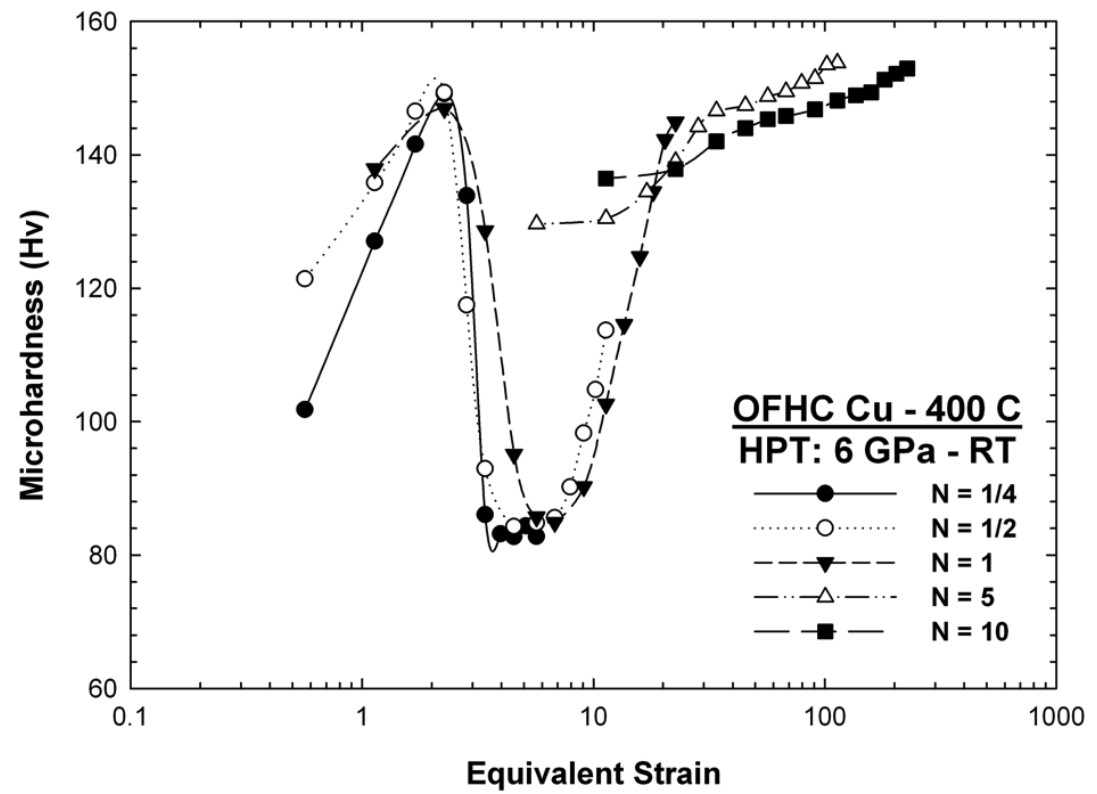

(b) 


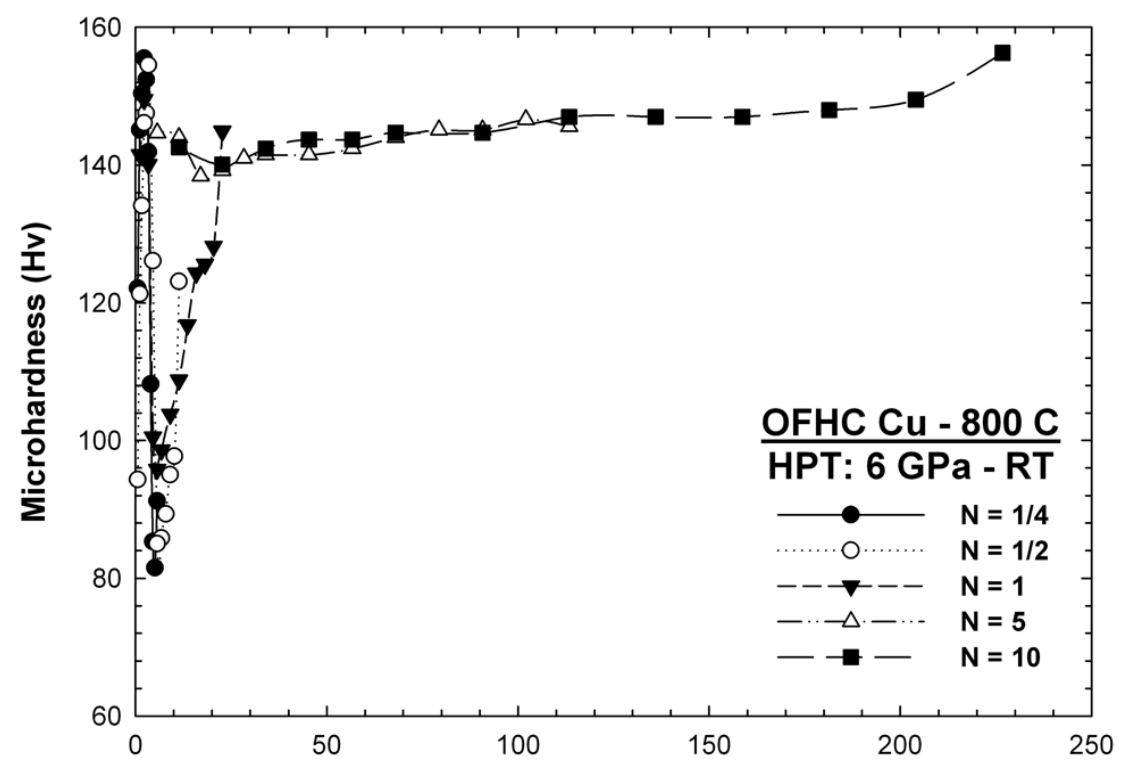

Equivalent Strain

(c)

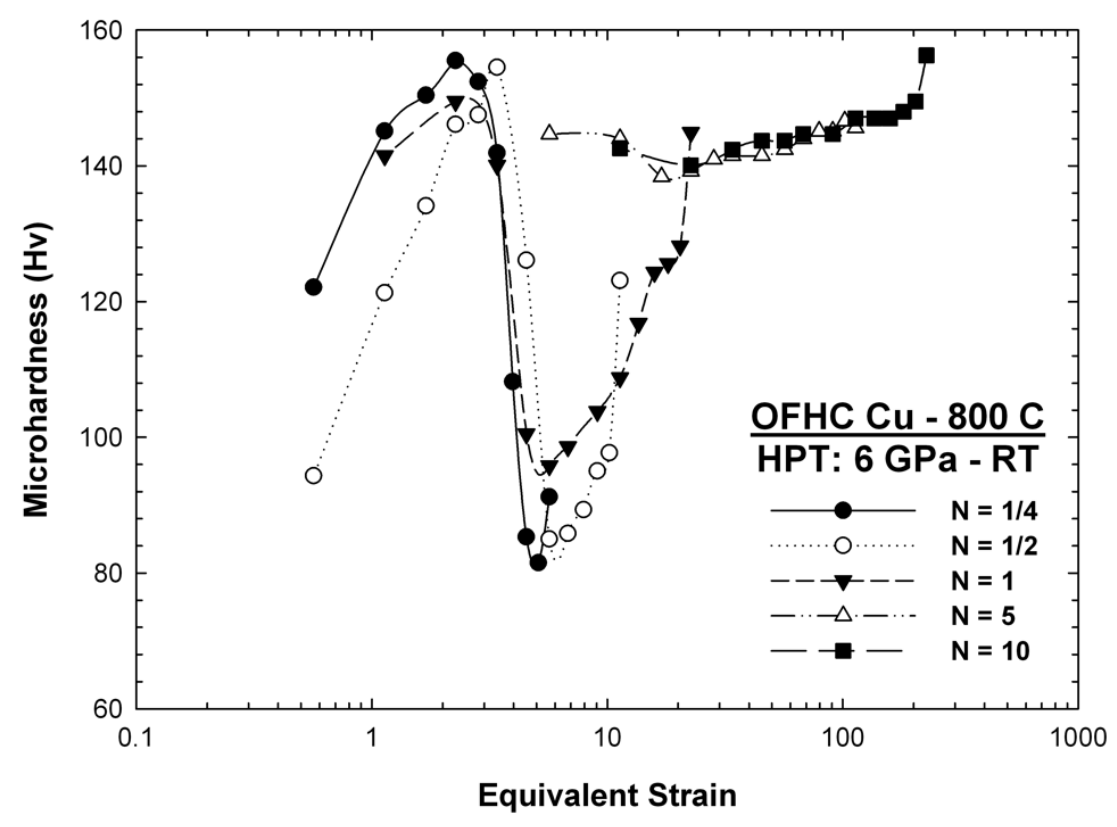

(d)

Fig. 7. Average Vickers microhardness plotted against equivalent strain for HPT Cu disks. Plots of Cu samples initially annealed at $400{ }^{\circ} \mathrm{C}$ using: (a) linear scale, (b) logarithmic scale. Plots of $\mathrm{Cu}$ samples initially annealed at $800{ }^{\circ} \mathrm{C}$ using: (c) linear scale, (d) logarithmic scale. 
Table 1. Average grain size of HPT Cu samples

\begin{tabular}{lcccccc}
\hline \hline \multirow{2}{*}{$\begin{array}{l}\text { No. turns / } \\
\text { Position }\end{array}$} & \multicolumn{5}{c}{ Average grain size $(\boldsymbol{\mu} \mathbf{m})$} \\
\cline { 2 - 7 } & Center & Mid-radius & Near edge & Center & Mid-radius & Near edge \\
\hline $\mathrm{nyyyyyy}$ & 6.85 & 1.16 & 0.75 & 15.7 & 0.68 & 0.57 \\
$\mathrm{~N}=1 / 4$ & 5.38 & 0.55 & 0.34 & 8.7 & 0.63 & 0.48 \\
$\mathrm{~N}=1 / 2$ & 4.71 & 0.44 & 0.32 & 8.4 & 0.56 & 0.47 \\
$\mathrm{~N}=5$ & 1.52 & 0.38 & 0.37 & 1.8 & 0.47 & 0.45 \\
$\mathrm{~N}=10$ & 0.97 & 0.34 & 0.28 & 0.79 & 0.38 & 0.34 \\
\hline \hline
\end{tabular}

